\title{
ГИРУДОТЕРАПИЯ В ЛЕЧЕНИИ ХРОНИЧЕСКОГО ГЕНЕРАЛИЗОВАННОГО ПАРОДОНТИТА
}

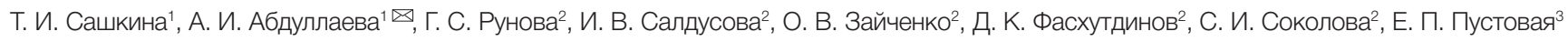

${ }^{1}$ Российский национальный исследовательский медицинский университет имени Н. И. Пирогова, Москва, Россия

2 Московский государственный медико-стоматологический университет имени А. И. Евдокимова, Москва, Россия

${ }^{3}$ Российский университет дружбы народов, Москва, Россия

\begin{abstract}
Хронический генерализованный пародонтит (ХГП) - заболевание, которое представляет определенные трудности для специалистов, поскольку характеризуется устойчивостью к применяемой терапии. Поэтому постоянно идет поиск препаратов и методов, позволяющих повысить эффективность лечения ХГП. Нередко возникают дополнительные проблемы, которые связаны либо с антибиотикорезистентностью, либо с повышенной чувствительностью к препаратам. Целью исследования было определить возможность использования гирудотерапии при консервативном лечении пациентов с ХГП. Было обследовано и пролечено 50 пациентов с ХГП, не имеющих соматической патологии. Они были разделены на две группы по 25 человек, примерно одного возраста. В каждой из групп сначала проводили лечение в соответствии с принятым стандартом: назначали профессиональные гигиенические процедуры, антимикробные и противовоспалительные препараты, обучали индивидуальной гигиене. Затем пациентам первой группы проводили курс гирудотерапии, состоящий из 6-8 процедур в течение месяца. При этом пациенты второй группы находились на диспансерном учете с целью контроля гигиены полости рта. Анализ полученных результатов показал более высокую эффективность гирудотерапии по отношению к группе сравнения. В группе, в которой использовали медицинские пиявки, происходило достоверное снижение папиллярно-маргинально-альвеолярного индекса (РМА), характеризующего интенсивность воспалительного процесса и кровоточивость тканей десны: на $32 \%$ при легкой степени тяжести, на 24\% при средней степени тяжести, на 6\% при тяжелой степени тяжести ХГП. Таким образом, показана эффективность гирудотерапии в консервативном лечении пациентов с ХГП, что позволяет рекомендовать этот метод в клиническую практику.
\end{abstract}

Ключевые слова: хронический генерализованный пародонтит, гирудотерапия, пародонтальные индексь

Информация о вкладе авторов: Т. И. Сашкина, А. И. Абдуллаева - планирование исследования, обработка полученных данных, редактирование рукописи; О. В. Зайченко и Е. П. Пустовая - обработка полученных данных, статистическая обработка данных, редактирование рукописи; С. И. Соколова, И. В. Салдусова - обработка полученных данных, редактирование рукописи; Д. К. Фасхутдинов, Г. С. Рунова - сбор данных, написание черновика рукописи.

Соблюдение этических стандартов: исследование было одобрено этическим комитетом РНИМУ имени Н. И. Пирогова (протокол № 981 от 24 июня 2019 г.).

$\triangle$ Для корреспонденции: Айтан Измировна Абдуллаева

ул. Островитянова, д. 1, г. Москва, 117997; aitanka@list.ru

Статья получена: 25.06.2019 Статья принята к печати: 25.07.2019 Опубликована онлайн: 18.08.2019

DOI: $10.24075 /$ vrgmu.2019.052

\section{HIRUDOTHERAPY IN TREATMENT OF CHRONIC GENERALISED PERIODONTITIS}

\author{
Sashkina $\mathrm{TI}^{1}$, Abdullaeva Al${ }^{1 凶}$, Runova GS², Saldusova IV², Zajchenko OV² , Faskhutdinov DK², Sokolova SI², Pustovaya EP \\ ${ }^{1}$ Pirogov Russian National Research Medical University, Moscow, Russia \\ ${ }^{2}$ Al Yevdokimov Moscow State University of Medicine and Dentistry, Moscow, Russia \\ ${ }^{3}$ Peoples Friendship University of Russia, Moscow, Russia
}

Chronic generalized periodontitis (CGP) is a disease associated with low susceptibility to the therapeutic protocols applied; practitioners tend to characterize it as a disease presenting certain difficulties. Therefore, the search for drugs and methods capable of increasing the efficacy of CGP therapy is an ongoing process. Additional problems, which have to do with either with antibiotic resistance or increased sensitivity to drugs, also occur quite often. This study aimed to assess the possibility of applying hirudotherapy in the context of conservative treatment of CGP. 50 patients with CGP without somatic pathology were examined and treated. The participants were divided into two groups $(n=25)$, all group members of about the same age. At the first stage, the treatment followed the accepted standard: professional oral hygiene procedures, antimicrobial and anti-inflammatory drugs, demonstration of proper personal oral hygiene routines. Then, first group went through a monthlong hirudotherapy course that consisted of 6 to 8 individual procedures. Second group was observed throughout this period with the aim to control the level of their compliance with the oral hygiene routines they were trained. Having analyzed the results, we found that hirudotherapy was more effective than what was prescribed to the second (control) group. The papillary marginal alveolar index (PMA), which reflects the severity of inflammation and gum bleeding, decreased significantly in the first group, where medicinal leeches were used: in the patients with severe CGP it went down by $6 \%$, in those with moderately severe CGP the index decreased by $24 \%$ and the participants whose CGP was only light had the PMA go down by $2 \%$. Thus, we have demonstrated the efficacy of hirudotherapy in the context of conservative CGP treatment, which allows recommending this method for inclusion into clinical practice.

Keywords: chronic generalized periodontitis, hirudotherapy, periodontal indices

Author contribution: Sashkina TI, Abdullaeva Al — research planning, data processing, manuscript editing; Zaychenko OV and Pustovaya EP — data processing, statistical data processing, manuscript editing; Sokolova SI, Saldusova IV — data processing, manuscript editing; Faskhutdinov DK, Runova GS — data collection, manuscript drafting.

Compliance with ethical standards: the study was approved by the Ethics Committee of Pirogov Russian National Research Medical University (protocol № 981 of June 24, 2019).

Correspondence should be addressed: Aytan I. Abdullaeva Ostrovityanova 1, Moscow, 117997; aitanka@list.ru

Received: 25.06.2019 Accepted: 25.07.2019 Published online: 18.08.2019

DOI: 10.24075/brsmu.2019.052 
Согласно данным ВОЗ, более 90\% населения Земли страдают хроническими воспалительными заболеваниями пародонта, имеющими длительное, упорное течение, приводящими к потере зубов, развитию хронических заболеваний желудочно-кишечного тракта, сердечнососудистой и других систем, что отрицательно сказывается на здоровье и качестве жизни пациентов [1, 2]. По этой причине пародонтит имеет не только общемедицинскую, но и социальную значимость и является актуальной проблемой в стоматологии. Существуют различные подходы к лечению пародонтита: наряду с обязательной антимикробной терапией и профессиональной гигиеной, используют хирургические, физиотерапевтические и альтернативные методы лечения, например натуропатию. По литературным данным при различных воспалительных заболеваниях применяют метод гирудотерапии. Слюна пиявок, обладая бактериостатическим действием, снижает микробную нагрузку на ткани пародонта, нормализует процессы гемостаза [3-6]. Это мотивировало нас изучить применение гирудотерапии при консервативном лечении ХГП $[4,5]$.

Целью работы было изучить эффективность использования гирудотерапии в комплексном консервативном лечении пациентов с ХГП.

\section{ПАЦИЕНТЫ И МЕТОДЫ}

В исследовании принимали участие 50 пациентов (21 мужчина и 29 женщин) в возрасте 32-52 года, страдающих ХГП легкой, средней и тяжелой степеней тяжести. Критерии включения: подписанное информированное согласие; наличие ХГП без сопутствующей соматической патологии в возрасте от 32 до 52 лет; прохождение обучения по уходу за раной; предварительная терапия в соответствии со стандартом, утвержденным Министерством здравоохранения РФ; Критерии исключения: наличие сопутствующей соматической патологии; возраст моложе 32 и старше 52 лет; некорректное выполнение рекомендаций врачей и несоблюдение гигиены ротовой полости; отсутствие предварительной терапии в соответствии со стандартом, утвержденным Министерством здравоохранения РФ. Пациенты были разделены на две группы, сопоставимые по клинико-функциональным характеристикам. В основную группу вошли 25 человек: 9 человек (36\%) с ХГП легкой

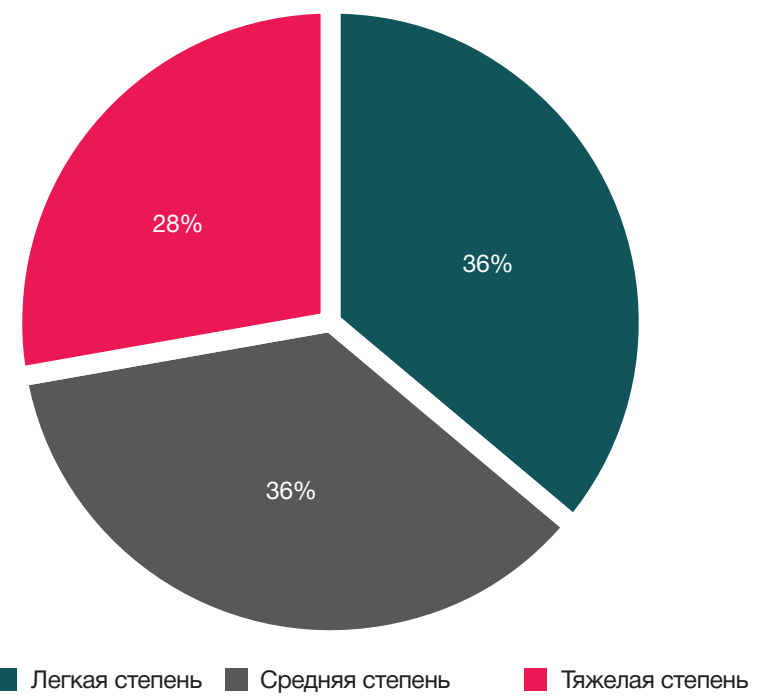

Рис. 1. Распределение пациентов с ХГП в группах в зависимости от степени тяжести генерализованного пародонтита $(n=25)$ степени тяжести, 9 человек (36\%) со средней степенью тяжести, 7 человек (28\%) с тяжелой степенью. Состав группы сравнения был аналогичен основной, и в нее было включено 25 человек (рис. 1). Все пациенты были без отягощенной соматической патологии. Эффективность лечения оценивали с помощью папиллярно-маргинальноальвеолярного (РМА) индекса, который позволяет контролировать степень воспалительного процесса.

Пациентам основной группы в течение недели проводили стандартное лечение, включающее антимикробную, противовоспалительную терапию, профессиональные гигиенические процедуры, а затем комплексное лечение, включающее гирудотерапию, которая заключалась в прикреплении пиявок к тканям пародонта в области воспалительного процесса (рис. 2). Использовали медицинские пиявки (Hirudo medicinalis) стандартного размера (0,6-1 г). Курс состоял из 6-8 процедур, проводимых 2 раза в неделю в течение месяца. Прикрепление пиявок проводили через 2 ч после приема пищи; пациентов предупреждали, что не должно быть специфического запаха из ротовой полости, напимер лука, чеснока, ополаскивателей для полости рта, кофе, кардамона. Кроме того, перед посещением стоматолога пациентам было запрещено в течение 5-6 ч курить и пользоваться парфюмерными средствами.

Пациентам контрольной группы проводили лечение по стандартному протоколу, вместо назначения гирудотерапии за ними было установлено диспансерное наблюдение с целью контроля соблюдения ими индивидуальной гигиены.

Статистическую обработку полученных результатов проводили с помощью критерия Стьюдента при достоверности результатов 95\% ( $p<0,05)$, используя программное обеспечение STATISTICA 10 (Раунд-рок; США).

\section{РЕЗУЛЬТАТЫ ИССЛЕДОВАНИЯ}

Анализ полученных результатов показал, что в первой группе применение медицинских пиявок позволяло усилить положительный результат, полученный в ходе стандартного лечения, при этом пародонтальные индексы имели тенденцию к дальнейшему снижению. При легкой степени тяжести ХГП после лечения РМА индекс достиг максимального достоверного снижения: с 21,89 $\pm 2,03$ до 14,89 $\pm 2,14$ ( $0<0,05)$. При средней

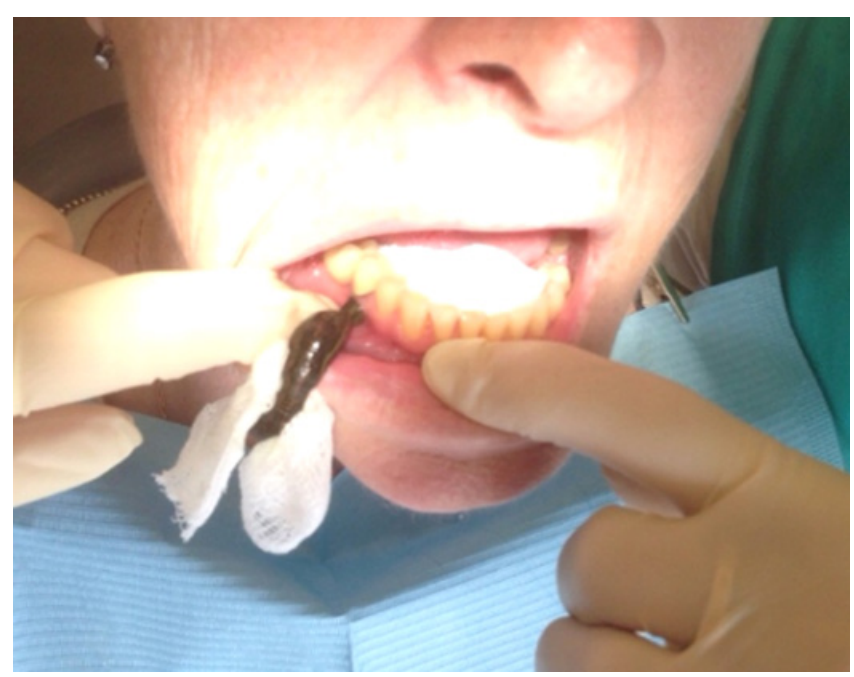

Рис. 2. Применение медицинских пиявок при лечении пациентов с ХГП. Медицинская пиявка стандартного размера прикреплена к тканям парадонта в области воспалительного процесса 


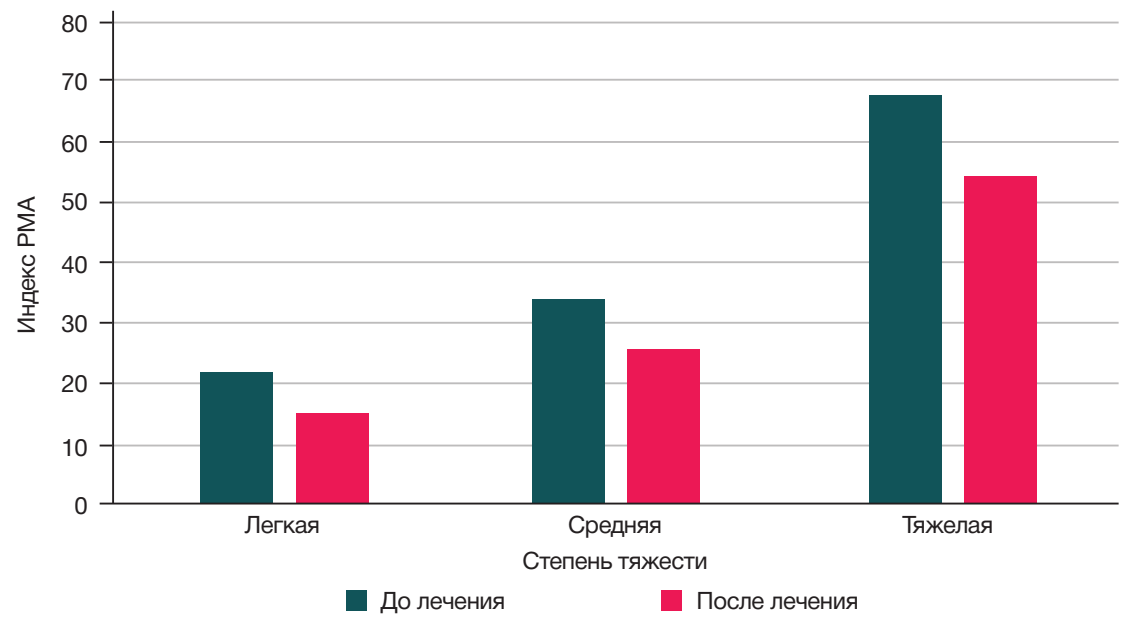

Рис. 3. Динамика индекса РМА в первой группе пациентов с ХГП ( $n=25)$

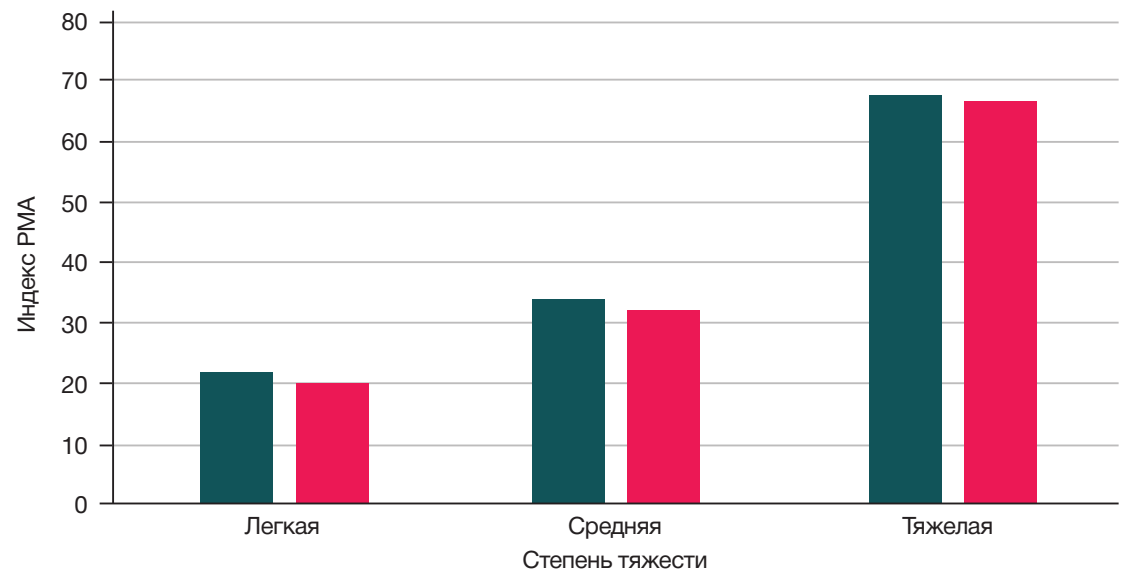

До лечения

П После лечения

Рис. 4. Изменение индекса РМА в группе сравнения пациентов с ХГП $(n=25)$

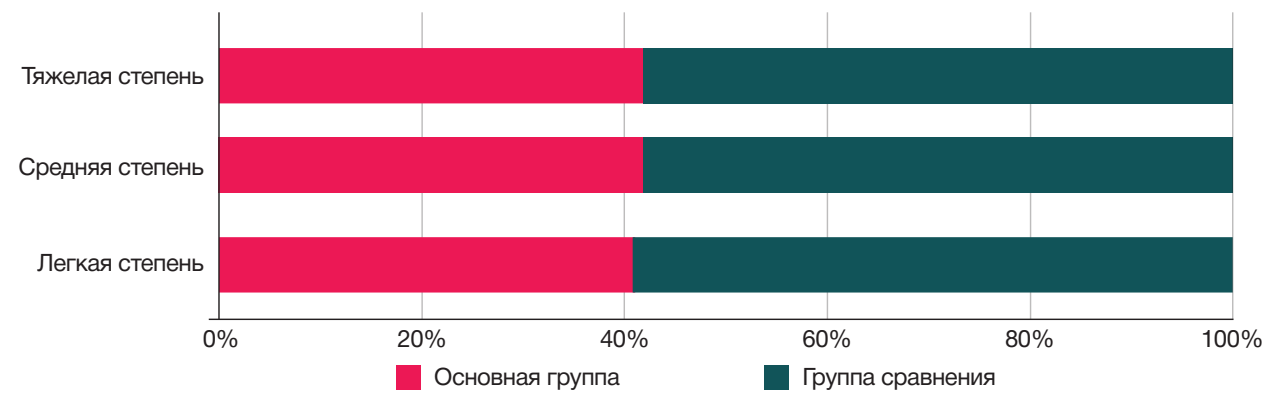

Рис. 5. Сравнительный анализ индекса РМА в основной группе и группе сравнения с ХГП после проведенного комплекса лечения

степени тяжести ХГП снижение индекса РМА происходило в меньшей степени: с 33,74 \pm 3,57 до 25,74 \pm 3,21. При тяжелой степени тяжести снижение индекса РМА было недостоверным: с 67,85 \pm 1,28 до 64,24 \pm 1,26, ( $\geq \geq 0,05)$ (рис. 3). В отличие от первой группы в группе сравнения результаты были менее выраженными, при легкой степени тяжести ХГП снижение индекса РМА было достоверным, но в меньшей степени, чем в первой группе: с 24,91 \pm 2,73 до 19,91 \pm 2,08 ( < 0,05). При средней степени тяжести - с 33,61 \pm 3,14 до 28,36 \pm 3,44. При тяжелой степени тяжести ХГП с 67,15 \pm 1,28 до 66,85 \pm 1,18 (рис. 4). При средней и тяжелой степенях тяжести ХГП результаты остались недостоверными (p $\geq 0,05)$. При сравнении величин, полученных в обеих группах, в основной группе выявлен более значительный клинический эффект при легкой и средней степенях тяжести ХГП (рис. 5).

\section{ОБСУЖДЕНИЕ РЕЗУЛЬТАТОВ}

Наше исследование в некоторой степени согласуется с работой, напечатанной в 2014 г., в которой при лечении пародонтита использовали гирудотерапию наряду с липосомным препаратом «Липин». Авторы показали большую эффективность используемого комплексного лечения по сравнению со стандартным, при этом вклад каждого из компонентов лечения в конечный результат не был оценен [6]. Мы показали, что изолированное применение гирудотерапии способствовало значительному купированию воспалительного процесса у больных с ХГП: снижению отека, артериальной гиперемии и кровоточивости десен. Лечение медицинскими пиявками позволило получить более выраженный и длительный эффект по сравнению с пациентами контрольной группы, что привело к увеличению продолжительности ремиссии. 
Положительная динамика всех изучаемых индексов оказалась более выраженной при легкой и средней степенях тяжести и была отмечена уже после 2-4 процедур гирудотерапии.

\section{ВЫВОДЫ}

Проведенное исследование продемонстрировало положительный терапевтический эффект гирудотерапии в лечении ХГП. Данная тактика лечения существенно повышает эффективность стандартных лечебных мероприятий и достоверно снижает воспалительный потенциал тканей пародонта: боль, зуд, кровоточивость десен. Учитывая растущую антибиотикорезистентность и высокую сенсибилизацию населения, в том числе к антибактериальным препаратам, гирудотерапия может быть методом выбора, а иногда одним из немногих в лечении определенных групп населения.

\section{Литература}

1. Сашкина Т. И., Порядин Г. В., Рунова Г. С., Дубровин Д. С., Фасхутдинов Д. К., Маркина М. Л., и др. Применение иммуномодулятора для коррекции воспалительного процесса в тканях пародонта у больных с хроническим генерализованным пародонтитом. Российская стоматология. 2016; 9 (3): 38-41.

2. Грудянов А. И., Ткачева О. Н., Авраамова Т. В., Хватова Н. Т. Вопросы взаимосвязи воспалительных заболеваний пародонта и сердечно-сосудистой патологии. Стоматология. 2015; 94 (3): 50-5.

3. Данилевский Н. Ф. Заболевания слизистой оболочки полости рта. М.: ГЭОТАР-Медиа, 2001.

\section{References}

1. Sashkina TI, Poryadin GV, Runova GS, Dubrovin DS, Faskhutdinov DK, Markina ML, et al. The application of an immunomodulator for the correction of the inflammatory process in periodontal tissues of the patients presenting with chronic generalized periodontitis. Rossiiskaya stomatologia. 2016; 9 (3): 38-41. In Russian.

2. Grudyanov Al, Tkacheva ON, Avraamova TV, Khvatova NT. The relationship between inflammatory periodontal diseases and cardiovascular diseases. Rossiiskaya stomatologia. 2015; 94 (3): 50-5. In Russian.

3. Danilevskij NF. Zabolevaniya slizistoj obolochki polosti rta. M.: GEOTAR-Media, 2001. In Russian.
4. Ц Цепов Л. М., Цепова Е. Л., Цепов А. Л. Пародонтит: локальный очаг серьезных проблем. Пародонтология. 2014; 3 (72): 3-10.

5. Trevilatto PC, de Brito RBJr, Scarel-Caminaga RM, de Souza AP, Sallum AW, Line SRP. Polymorphism in the tumor necrosis factoralpha gene (TNFA-308 G/A) is not associated with susceptibility to chronic periodontitis in a Brazilian population. Dentistry 3000. 2015; (3): 1

6. Абдувалиев А. А., Дауреханов А. М. Гирудотерапия в комплексном лечении больных реактивным артритом. Вестник КазНМУ. 2017; (1): 249-52.
4. Tsepov LM, Tsepova EL, Tsepov AL. Marginal periodontitis: local focus of serious problems. Parodontologia. 2014; 3 (72): 3-10.

5. Trevilatto PC, de Brito RBJr, Scarel-Caminaga RM, de Souza AP, Sallum AW, Line SRP. Polymorphism in the tumor necrosis factoralpha gene (TNFA-308 G/A) is not associated with susceptibility to chronic periodontitis in a Brazilian population. Dentistry 3000. 2015; (3): 1.

6. Abduvaliev AA, Daurekhanov AM, Hirudotherapy as a complex treatment of patients with reactive arthritis. Bulletin of KazNMU. 2017; (1): 249-52. 